\title{
以2.
}

Journal of Rehabilitation Research

and Development Vol. 22 No. 3

BPR 10-42 Pages 25-41

\section{Wheelchair tire rolling resistance and fatigue}

\author{
JAMES J. KAUZLARICH, PH.D.; JOHN G. THACKER, PH.D. \\ Department of Mechanical and Aerospace Engineering, and the \\ Rehabilitation Engineering Center; University of Virginia, \\ Charlottesville, Virginia 22903
}

\begin{abstract}
The hysteresis loss theory of rolling resistance is developed for solid rubber wheelchair tires. The analysis is used to correlate test data for a clayfilled natural rubber and a polyurethane tire material. A discussion of tire rolling work, hysteresis loss factor measurement, and rolling loss measurement is presented. An example calculation of rolling resistance for a polyurethane tire is given in detail. The subject of solid rubber tire design is developed on the basis of recommended fatigue life theory and practice. It is shown that polyurethane tires have a useful fatigue life due to a high shear modulus at useful values of hardness. This characteristic of polyurethane, if exploited, is predicted to lead to a tire with a lower rolling resistance than other wheelchair tires available. The effect of surface roughness on rolling resistance is briefly discussed and some experimental results are listed. The purpose of this paper is to give the rehabilitation engineer the means for wheelchair tire rolling resistance and fatigue life design and the methods to assess the tire characteristics when a tire design is modified or a new tire material is contemplated. Other important design factors, such as wear and chemical degradation, are not discussed, but references are suggested for information on these topics. As in most research and development projects, this study raises problems which need further work. For example, the fatigue properties of the rubber compounds employed in this application are not completely understood; this subject is planned for future investigation.
\end{abstract}

\section{INTRODUCTION}

The earliest recorded study of rolling devices is that of Leonardo da Vinei (16). In 1492, he

\footnotetext{
This work was supported by National Institute of Handicapped Research Grant G00-8300-72.
}

investigated thrust ball and roller bearings and sliding frictional resistance using an inclined plane. Da Vinci determined that his thrust bearing would work with low rolling resistance only if the rolling elements were kept from touching each other during operation by a separator. Prior to this date, ancient Greeks and Romans used crude rolling element bearings.

Almost 300 years later, in 1785 , Coulomb (1) experimented with cylinders made from lignum vitae and elm rolling along oak guides. His research led to the concept that the coefficient of rolling resistance $(f)$ defined as the ratio of the driving force $(F)$ to the normal load $(P)$ is inversely proportional to the radius of the cylin$\operatorname{der}(\mathrm{R})$ where $k$ is a material constant, i.e.

$$
f=\frac{\mathrm{F}}{\mathrm{P}}=\frac{k}{\mathrm{R}}
$$

Kragelsky et al. (12) reviewed the extensive literature on rolling friction and divided the studies into those primarily concerned with 1) load and surface roughness, 2) microslip in the contact area that produces frictional forces, and 3) rolling resistance due to hysteresis losses associated with deformation of the material during rolling.

In a recent publication on contact mechanies, Johnson (11) developed the subject of rolling resistance. He found that the various sources of energy dissipation can be classified under the same headings as Kragelsky's (12). Johnson showed that for free rolling (i.e., no braking or tractive forces) and on flat or somewhat conform- 
ing surfaces, microslip is negligible compared with the effect of inelastic deformation or hysteresis of one or both bodies.

Rolling resistance is also a function of the surface roughness. The rolling resistance of a smooth, flat treadmill is significantly different than that of a typical concrete sidewalk. However, surface roughness is neglected at first in the following analysis. Thus, it is the inelastic hysteresis of the deformed material that is the main cause of rolling resistance in wheelchair tires on smooth surfaces.

Because hysteresis losses in the rubber account for almost all of the rolling losses, any surface films of oil or water will not affect these losses.

Kragelsky (12) attributes the initial concept of hysteresis rolling loss to the French engineer, Dupuit, who developed it in 1837. However, it was the work of Tabor (19) in 1955 that produced the first analytical expressions for rolling resistance that were useful to the engineer. This work was further developed by Giles and Saeby (4) and Greenwood and Tabor (7); it was essentially completed in 1961 by Greenwood, Minshall, and Tabor (6).

For a rigid sphere rolling on an elastic smooth surface, Greenwood et al. (6) show data that can be correlated by the dimensionless groups

$$
f \frac{\mathrm{G}}{\tau_{y}} \propto \frac{\mathrm{G}^{2} \mathrm{P}}{\tau_{y}^{3} \mathrm{R}_{\mathrm{e}}^{2}}
$$

where $G$ is the shear modulus, $P$ is the load, $R_{e}$ is the equivalent radius, and $\tau_{y}$ is the yield stress in shear. For a wheelchair tire with $R$ the radius of the wheel and $R^{\prime}$ the profile radius of the tire tread (see Fig. 10), an equivalent radius for $\mathrm{Eq} .2$ is given by Greenwood (5) as

$$
R_{e}^{2}=\left[R R^{\prime}\left(\frac{2 R R^{\prime}}{R+R^{\prime}}\right)\right]^{2 \prime \prime}
$$

Johnson (11) found that Eq. 2 is linear and proportional to the material loss factor for elastic materials that have a yield stress up to a value of the contact stress Johnson Number $\left(\mathrm{G}^{*} \mathrm{P} / \tau_{\mathrm{y}}^{3}\right.$ $\left.\mathrm{R}^{2}\right)=300$. Above $J_{0}=300$, the rolling elements are plastically deformed and the rolling resistance rises rapidly.

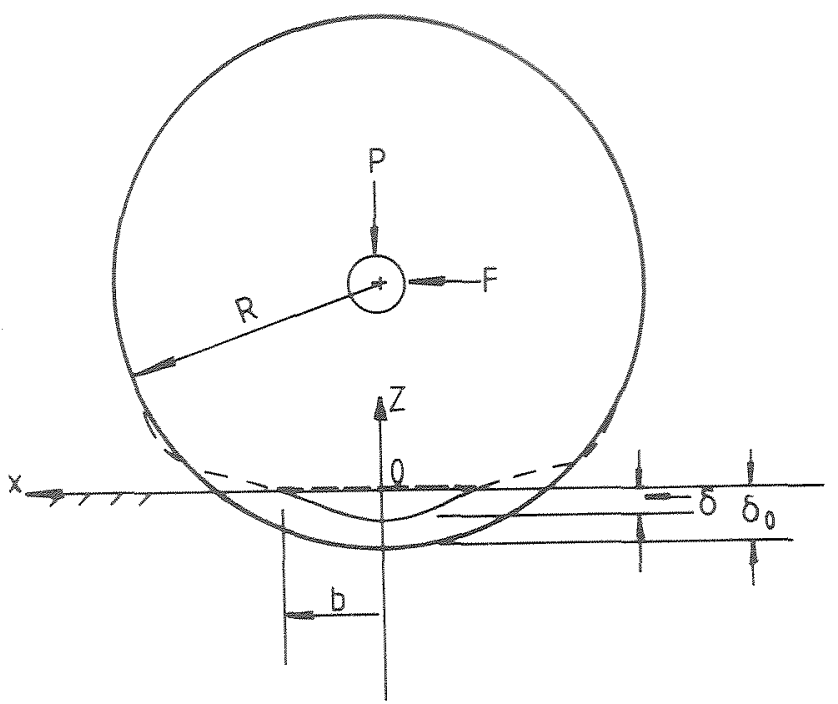

\section{FIGURE 1}

Top: Deflections during rolling of a flexible cylinder on a rigid surface. $P=$ nomal load; $F=$ force; $R=$ wheel radius; $\mathrm{x}, \mathrm{z}=$ axes; $\delta=$ loaded deflection, $\delta_{0}=$ initial deflection at center of contact; $\mathrm{b}=$ semicontact length. Bottom: Wheelchair tire footprint.

Tire materials can be elastic, where stress and strain are independent of time, or viscoelastic, where stress and strain are time dependent. To a certain extent, all tire tread materials are viscoelastic. However, at low rolling speeds, the relaxation time constant of the material $\left(\tau_{\mathrm{m}}\right)$ is short compared with the time $\left(\tau_{\mathrm{r}}\right)$ for which the rolling contact is loaded; $\tau_{\mathrm{r}}=d / V$ where $d=2 a$, $a$ is the semicontact width in the direction of rolling of the elliptical tire footprint, and $V$ is the wheelchair velocity. Thus, when $\tau_{\mathrm{m}} \ll \tau_{\mathrm{r}}$ a viscoelastic material can be treated like an elastic material, which is a much simpler analysis. This is the case for the usual wheelchair tires of compounded natural rubber or polyurethane. The ratio $\tau_{m} / \tau_{r} \equiv$ Deborah Number, and De $\ll 1$ is the case above.

This paper studies the rolling resistance of wheelchair tires of the solid "airless" type. Pneumatic tires are more complicated to analyze since energy losses take place in the casing as well as the tread. There is extensive literature on pneumatic tires (see ref. 12a), and a comprehensive review is given by Schuring (17).

In this paper the equations for calculating the rolling resistance of solid tires are derived and theoretical results are compared with test data. Some design limitations for fatigue are reviewed, and the results are used to suggest improvements 
in existing wheelchair tires. Finally, the theory and calculations are laid out so that the wheelchair tire design engineer can apply them with ease. In the process of developing the analysis for wheelchair tires, we derived several new equations following the hysteresis loss concepts of Tabor and co-workers (5-7).

\section{THEORY}

\section{Rolling Work}

When a solid elastic tire is first compressed on a rigid surface due to a normal load $P$, the initial deflection at the center of contact is shown in Figure 1 as $\delta_{0}$. The rubber is essentially incompressible, and the tire bulges slightly and is deflected so that the tread contacts the surface between $\pm b$, as shown. Now when the tire rolls under the influence of the force $F$, each element of tread that comes into contact with the surface carries the load over the contact region between $\pm b$. Work is done on the tread as it is deflected by the amount $\delta$ between $+\mathrm{b}$ to 0 . Between 0 to $-b$, the tread is unloaded and does work against the contacting surface. If the work done in compressing the front half of the contact during rolling is equal to the work given up by the rear half of the contact surface, the rolling resistance (F) would be zero. However, the tire material is not perfectly elastic. There is a loss of energy, called hysteresis loss, in the deformed material that must be compensated by the work of rolling resistance. Hysteresis loss mainly appears as heat in the tire.

It is assumed that the hysteresis losses at the hub are negligible in comparison to those at the contact with the rigid surface since the stress at the hub is low. Furthermore, in applying the theory, it will be assumed that the hysteresis losses in the tire material at the rim of the wheel are negligible in comparison to the losses in the tire at the point of contact with the floor.

During rolling, the elastic work energy involved in deforming the tire tread between $b$ to zero is $\phi$ per unit distance of travel $s$, and $\alpha$ represents the fraction of energy dissipated due to material hysteresis, where $\alpha \equiv$ hysteresis loss factor, then

$$
\mathrm{F} s=\alpha \phi s
$$

For small strains and small hysteresis losses during rolling, the pressure distribution over the contact region is given by the Hertz equations, e.g., the equation for a linear-elastic material $(9$, p. 377).

The analysis for Eq. 4 is given in APPENDIX A and results in the following equation for rolling resistance

$$
\mathrm{F}=2.5 \alpha_{\mathrm{s}} \frac{3}{16} \frac{\mathrm{P}^{\mathrm{u}_{3}}}{\mathrm{R}} m\left[\frac{3}{2} \frac{\mathrm{R} \mathrm{R}^{\prime}}{\left(\mathrm{R}+\mathrm{R}^{\prime}\right)} \frac{\left(1-\vec{\psi}^{2}\right)}{\mathrm{E}}\right]^{\mathrm{t}}
$$

In Eq. $5 v$ is Poisson's ratio, $\mathrm{E}$ is the modulus of elasticity, $R$ is the wheel radius, $R^{\prime}$ is the undeformed tread radius (see Fig, 10), $\mathrm{P}$ is the load, $\alpha_{s}$ is the hysteresis loss factor in shear, and $m$ is a constant for a given tire geometry, as described next.

The calculation of $m$ is based on the Hertz theory. For a wheelchair tire with a tire geometry factor $(\psi)$ of

$$
\psi=\frac{R-R^{\prime}}{R+R^{\prime}}
$$

the value of $m$ can be found from the following polynomial fit of the Hertz equations

$$
\begin{aligned}
m & =1.00068-0.82769 \psi+24.60152 \psi^{2} \\
& -126.41967 \psi^{3}+291.5357 \psi^{\prime}-307.32116 \psi \\
& +122.85733 \psi(0 \leqslant \psi \leqslant 0.94)
\end{aligned}
$$

The following example calculation demonstrates the use of these equations for finding the rolling resistance.

Let $\mathrm{R}=0.3048 \mathrm{~m}$ (12 in), $\mathrm{R}^{\prime}=0.0254 \mathrm{~m}$ (1 in), $\mathrm{P}=490 \mathrm{~N}(110 \mathrm{lbf}), v=1 / 2$, and take typical values for polyurethane of $\mathrm{E}=9.6 \mathrm{MPa}$ and $\alpha_{\mathrm{s}}=0.15$, as shown in Figures 6 and 7 . From Eq. 6, calculate

$$
\psi=\frac{0.3048-0.0254}{0.3048+0.0254}=0.846
$$

Then, from $\mathrm{Eq} .7, m=2.563$, and $\mathrm{F}$ from $\mathrm{Eq} .5$ is

$$
\begin{aligned}
F= & 2.5(.15) \quad \frac{3}{16} \frac{490^{+3}}{0.3048} \\
& 2.563\left[\frac{3}{2} \frac{0.3048 \times 0.0254}{(0.3048+0.0254)} \frac{(1-0.5)}{9.6 \times 10^{i}}\right] \\
= & 3.2 \mathrm{~N}(0.72 \mathrm{lbf}) \text { per wheel }
\end{aligned}
$$

Thus, the rolling resistance of the two rear 
wheels is $6.4 \mathrm{~N}$. Assuming the front caster load is $310 \mathrm{~N}$ per wheel, with $\mathrm{R}=0.1016 \mathrm{~m}$ (4 in), $\mathrm{F}=3.5 \mathrm{~N}$ per caster wheel, the rolling resistance of the wheelchair with a laden weight of $1300 \mathrm{~N}$ (292 lbf) is $\mathrm{F}=13.4 \mathrm{~N}$ (3.0 lbf). This result is in reasonable agreement with experimental tests on a treadmill (20).

\section{Loss Factor}

The theory of Eq. 5 for the rolling resistance assumes that the hysteresis loss factor $\alpha$ is a material constant. Johnson (11), Freakley and Payne (3) and others show that the loss factor will vary with strain (stress) for metals and rubbers and with frequency of loading and temperature for rubbers.

The hysteresis loss factor appropriate to the complex cycle of stress experienced by the material in rolling contact is not identical to that measured in either a simple tension-compression cycle or a simple shear cycle. However, Greenwood et al. (6) have proposed a way in which they may be approximately related. With this in mind, measurement of a material loss factor must be related to the temperature, strains, and frequencies encountered during rolling.

One of the oldest and most often used devices for measuring dynamic properties of a material is the torsional pendulum. By using the test material as the spring and varying the mass to control the frequency, the logarithmic decrement of the decaying amplitude can be related to the loss factor. Figure 2 is a typical amplitude plot from a torsional pendulum in which the damping is due to losses in the spring test material (other losses such as windage are negligible). The curve is similar to that from a hydraulically damped spring-mass system. It is possible to apply the logarithmic decrement theory presented by Thompson (21, p. 30). Particularly, the definition of the logarithmic decrement applicable to Figure 2 is

$$
\lambda=-\frac{1}{n} \ln \frac{\left|\theta_{n}\right|}{\theta_{0}}
$$

where $\left|\theta_{n}\right|$ represents the absolute value of amplitude after $n$ cycles or half-cycles have elapsed.

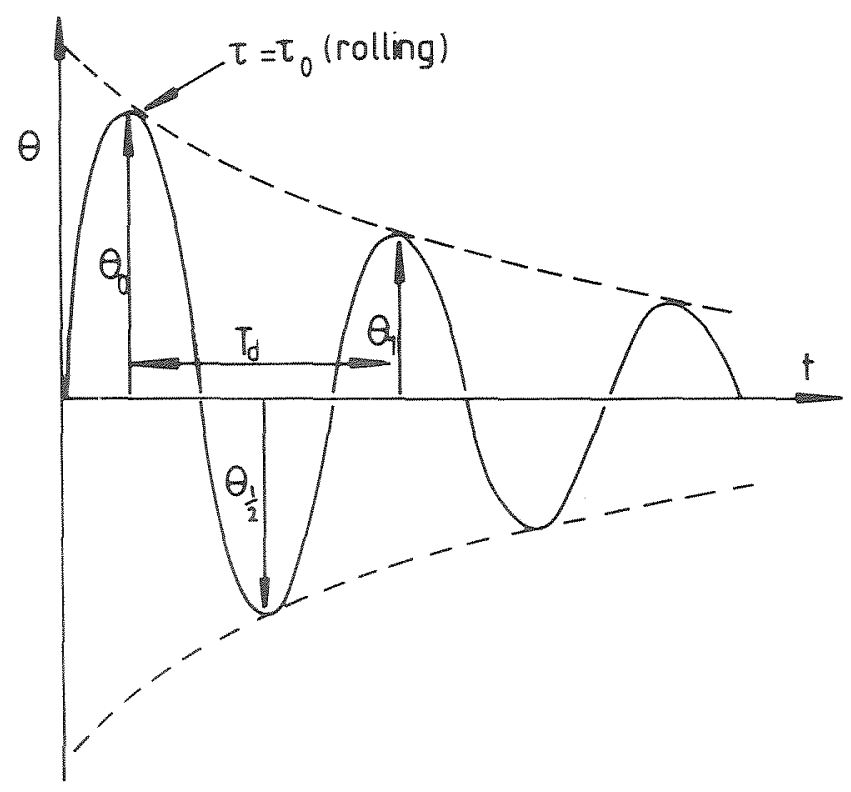

FIGURE 2

Top: Torsional pendulum angular amplitude $(\theta)$ versus time ( $t)$. Bottom: Relation between loss factor in rolling to torsion.

The angular strain energy stored in the test material spring is

$$
\mathrm{U}=\frac{\mathrm{GJ}|\theta|^{2}}{2 \mathrm{~L}}
$$

where $G$ is the modulus of rigidity, $J$ is the polar moment of inertia, and $\mathrm{L}$ is the length of the test material spring.

A static (fixed torque) torsional loss factor is measured by calculating the loss for a half-cycle and dividing by the input energy for that halfcycle. Greenwood (5) suggests that the dynamic loss factor can be measured in a similar manner, by letting

$$
\alpha_{S}=\frac{\mathrm{U}_{0}-\mathrm{U}_{1,2}}{\mathrm{U}_{0}+\mathrm{U}_{1 / 2}}
$$

Substituting Eq. 11 into Eq. 12 gives

$$
\alpha_{s}=\frac{1-\left(\frac{\left|\theta_{1,2}\right|}{\theta_{0}}\right)^{2}}{1+\left(\frac{\left|\theta_{1,2}\right|}{\theta_{0}}\right)^{2}}
$$

From Eq. 10 with $n=1 / 2$, Eq. 13 becomes

$$
\alpha_{s}=\frac{1-\exp (-\lambda)}{1+\exp (-\lambda)}
$$




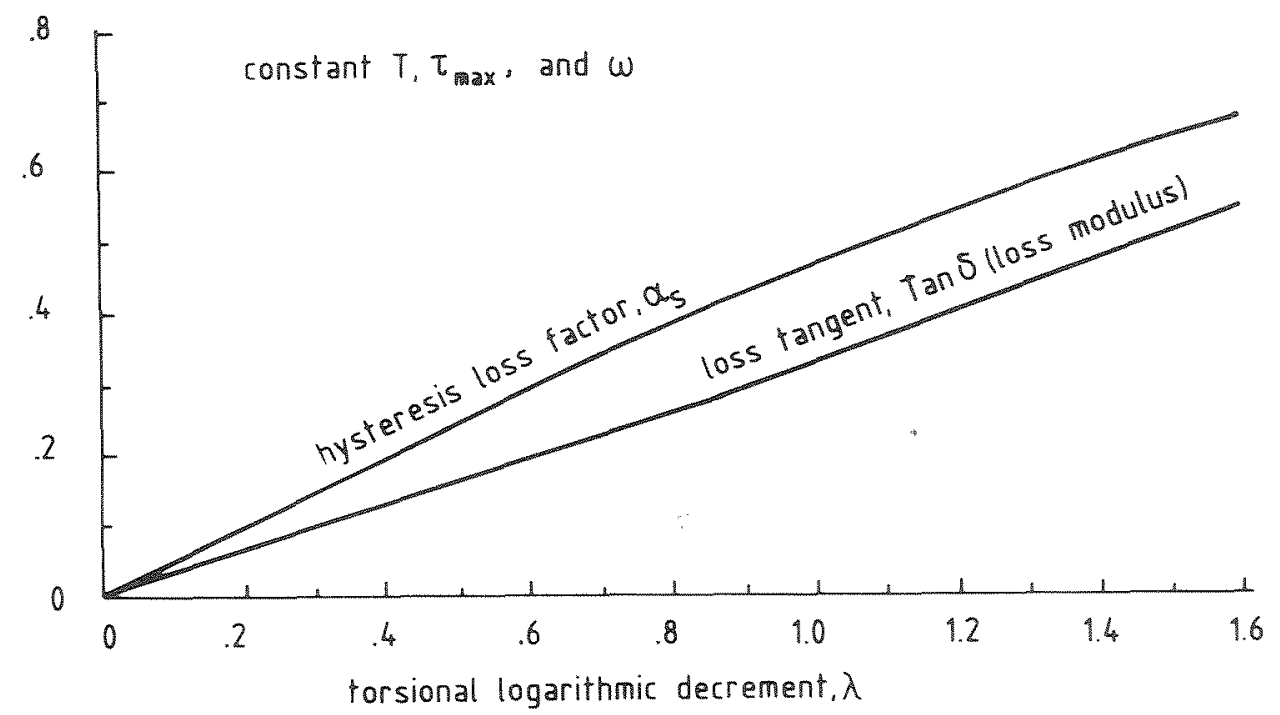

FIGURE 3

Torsional hysteresis loss factor and loss tangent relation.

Equation 14 is used to calculate the wheelchair tire material $\alpha_{s}$ used in Eq. 5 with very good results. By using Eq. 13 over several half-cycles, one can measure $\alpha_{s}$ with respect to the maximum value of stress. By varying the mass of the torsional pendulum, one can study the effect of frequency on $\alpha_{s}$. The shear stress range of interest for wheelchair tires is from 0.1 to 0.5 MPa (see data in RESULTS), and frequency ranges from zero to $100 \mathrm{~Hz}(\omega=V / 2 a, a=0.02 \mathrm{~m}$, and $V=4 \mathrm{~m} / \mathrm{s}$.

The losses in the test material spring of a torsional pendulum can also be measured by considering the phase angle of the vibration, as shown by Young (25, p. 234). In this approach, the loss tangent is related to the logarithmic decrement as

$$
\tan \delta=\frac{\frac{\lambda}{\pi}}{1-\frac{\lambda^{2}}{4 \pi^{2}}}
$$

Since Eqs. 14 and 15 are related through $\lambda$, the relation between $\alpha_{s}$ and $\tan \delta$ is shown in the plots of Figure 3.

\section{Rolling Losses}

If only the shear loss factor is used in the calculation for rolling resistance, theoretical re- sults are found to be too low in comparison with those from experiments. Greenwood et al. (6) postulated that the losses are proportional to the square of the length of the stress path of deformation of the material during a cycle of loading. For a cylinder under static loading, this plane strain case gives three independent stresses on any element in the deformed material. Of these stresses, the shear stress $\tau_{\mathrm{zx}}$ and the maximum shear stress $\mathrm{S}=1 / 2\left(\sigma_{\mathrm{x}}-\sigma_{\mathrm{y}}\right)$ contribute to energy losses. The hydrostatic pressure component of stress does not contribute to energy losses. Greenwood et al. (6) calculated the total loss stress path squared in a cycle associated with rolling. They determined that the total loss factor in rolling for a cylinder was 3.5 times the loss factor in pure shear. Based on test data, he found the rolling loss factor for a sphere is 2.5 times the loss factor in pure shear. This result is further discussed in APPENDIX A, and a plot of the rolling/ shear ratio for all possible cases is shown in Figure 2A.

As a further demonstration of these observations, the loss stresses under a cylinder and a sphere are plotted, along with that for a torsion test, in Figure 4. The plot shows the torsion stress path used to determine $\alpha_{s}$. It also shows half of the stress path of a cylinder and a sphere along the $x$ axis of rolling and at a depth $z$ in the deformed material. The depth, $z$, corresponds to the depth of stress $\tau_{0}$, the maximum orthogonal 
shear stress amplitude, e.g., see Harris (9) for $\tau_{0}$. The equations for stress due to loaded cylinder were from Poritsky (15), and those for loaded sphere were from Hamilton (8). Although the curves in Figure 4 do not represent the total loss stress path, the square of the stress path shown is roughly proportional to that determined by Greenwood et al. (6) of $\mathrm{L}^{2}$ (torsion): $\mathrm{L}^{2}$ (sphere) $: \mathrm{L}^{2}$ (cylinder) $=1: 2.5: 3.5$.

In the case of wheelchair tires, the results given in Figure $2 \mathrm{~A}$ show that a constant factor of 2.5 times the loss factor in shear applies. This loss factor is used in Eq. 5 for calculating rolling resistance.

\section{EXPERIMENTAL RESULTS}

\section{Tire Properties}

The word mbber is used for a group of mate- rials with the ability to undergo large deformations and to recover quickly. In the application of rubber for solid wheelchair tires, two materials are now in common use. The older material, gray rubber, is cured natural rubber reinforced with about 50 percent (by weight) microparticle clay. The newer material is polyurethane. Freakley and Payne (3) give a state-of-the-art review of theory and practice using rubber.

Wheelchair tire materials have a modulus of rigidity $\mathrm{G}$ on the order of $3 \mathrm{MPa}$; Figure 5 shows a typical stress/strain curve for rubber in tension/ compression and in shear. Figure 5 shows that the rubber is essentially a linear-elastic material in shear.

In tension/compression for constrained loading, i.e., when the test block is bonded between metal grips, the material is nonlinear. When the metal grips are not bonded and lubricated, allowing free compression, the compression stress-

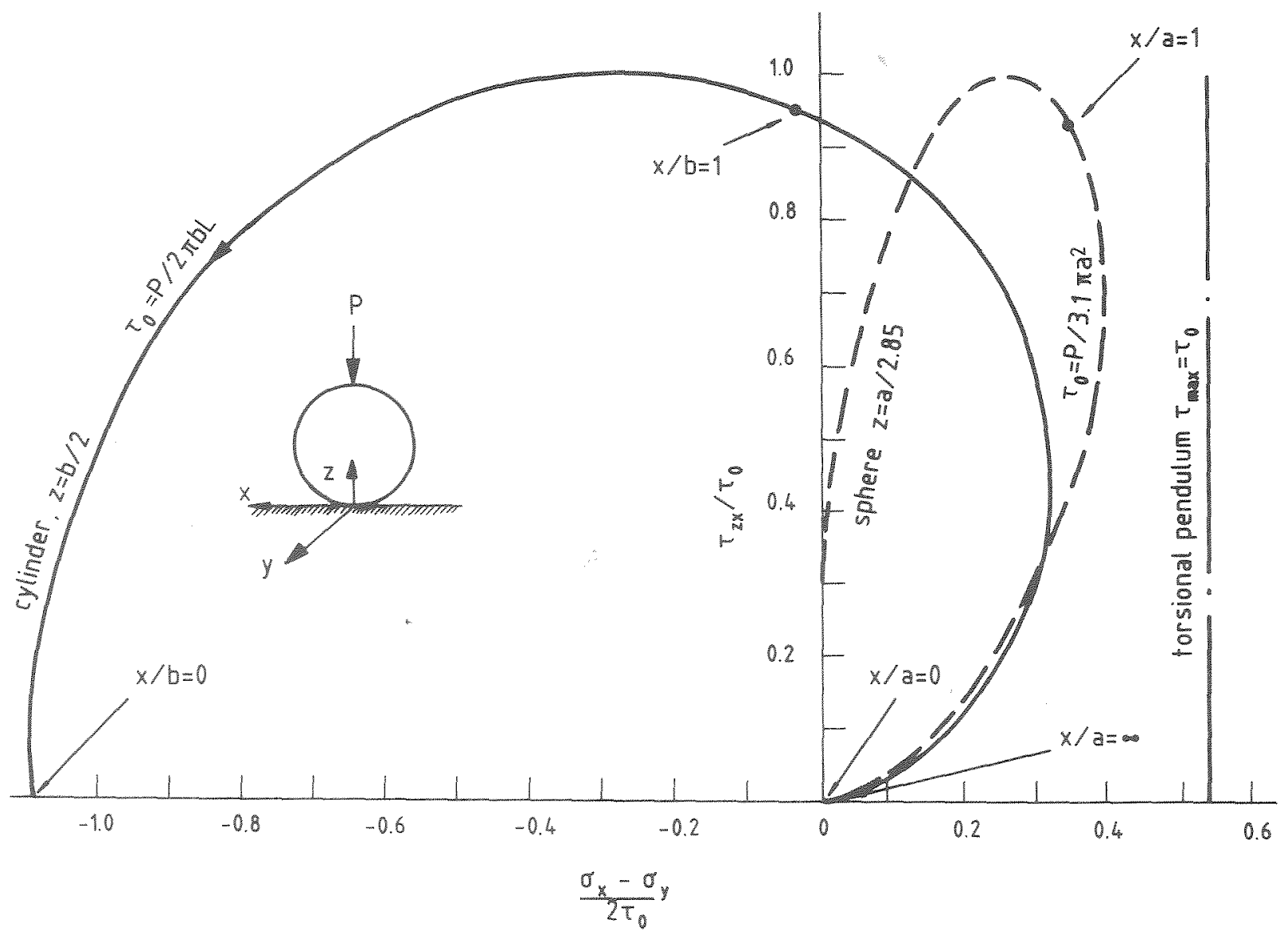

FIGUUE 4

Shear stress path for rolling elements at depth $(z)$ of maximum orthogonal shear stress amplitude. 


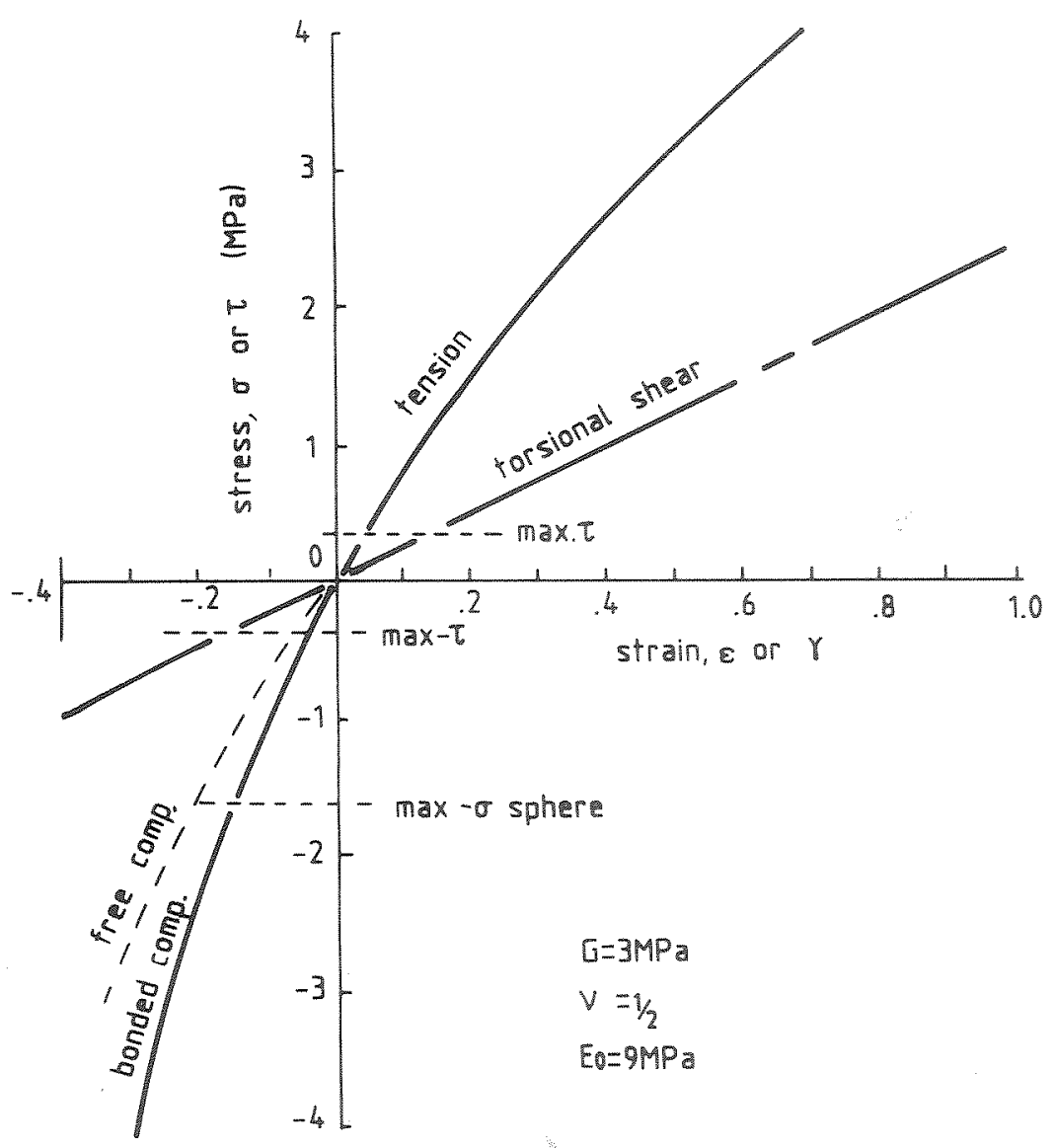

\section{FIGURE 5}

Typical stress-strain curves for wheelchair tire material and recommended maximum design stress for long fatigue life. strain curve is also approximately linear elastic for small strain. Thus, for tire loading during rolling, which is essentially free compression and shear, the material can be treated as linear elastic.

The maximum fatigue design stress in shear and the related maximum stress for a sphere is shown in Figure 5 and is discussed under tire design (see DESIGN ANALYSIS).

The two wheelchair tire materials tested were subjected to torsional stress. The test results are shown in the shear stress-strain plot in Figure 6 with the values of $\mathrm{G}$ given. In general, rubber materials have a Poisson's ratio near the upper limit for materials of $\nu=1 / 2$. Freakley and Payne (3) give a working Poisson's ratio for cured and reinforced natural rubber of $\nu=0.499$. The relationship between $\mathrm{G}$ and $\mathrm{E}$ for a linear-elastic material is

$$
\mathrm{E}=2 \mathrm{G}(1+v)
$$

and when $F$ is calculated at the zero of the stressstrain curve it is noted as $\mathbb{E}_{0}$. Figure 6 shows that the usual wheelchair tire materials have a $\mathrm{G} \cong 3 \mathrm{MPa}$. Larger values of $\mathrm{G}$ and $\mathrm{E}$ would give a lower rolling resistance but make a stiffer tire.

Another property of the material needed for calculating rolling resistance is the hysteresis loss factor in shear. A torsional pendulum was used to measure the loss factor as outlined in the preceding section. The torsional pendulum results are shown in Figure 7 along with data from the rolling resistance tests given in Figures 8 and 9. The general shape of the curves for $\alpha_{s}$ is predicted by using data from Freakley and Payne (3, Fig. 3.16) and heavily weighting the rolling resistance measurements indicated by a slash.

The frequency range of shear loss factor data is 1 to $30 \mathrm{~Hz}$. Freakley and Payne give the tan $\delta$ loss versus frequency for filled natural rubber ( 3 , Fig. 3.3) and find that the loss factor is constant up to $100 \mathrm{~Hz}$ at room temperature. Higher temperatures will shift the loss factor versus frequency curve to the left, reducing the range over which the loss factor is constant. Thus, at the relatively low rolling speeds of wheelchairs, it 
Journal of Rehabilitation Research and Development Vol. 22 No. 3 July 1985

appears that the tire contact frequency is below the region where the loss factor is frequency dependent for room temperature conditions. Therefore, the material can be treated as linear elastic.

The method for calculating the shear stress needed to use Figure 7 for rolling-resistance calculations is given in the next section.

\section{Rolling Resistance}

Figures 8 and 9 give the rolling resistance test results and the theoretical curve based on Eq. 5 . Besides the geometry of the tire and modulus of the material, the maximum shear stress of the tire deformation must be calculated to use Figure 7 to predict the shear loss factor.

Harris (9, Fig. 5.14) plots $\tau_{0}$, the maximum orthogonal shear stress amplitude, from the Hertz analysis versus b/a of the elliptical contact area for a tire. This is the maximum shear stress experienced by the tire deformation and is believed to be the main cause for fatigue failure due to rolling.

The wheel bearing for the test wheels is a sealed, grease-filled, ball bearing. The rolling resistance of these bearings is mainly due to the seals and is on the order of $0.1 \mathrm{~N}$ when the bearing is properly adjusted. The wheel bearing rolling resistance is not included in the test results.

The value $b / a$ is a function of the tire geometry as follows. From Eq. 6,

\section{FIGURE 6}

Shear stress-strain of wheelchair tire materials, semistatic $(\approx 1 \mathrm{~Hz})$, room temperature.

$$
\psi=\frac{\mathrm{R}-\mathrm{R}^{\prime}}{\mathrm{R}+\mathrm{R}^{\prime}}
$$

The coefficient on the equation for $b$ is $b^{*}$ in Harris (9) and $n$ in Timoshenko and Goodier (22) where

$$
b=n\left[\frac{3}{2} \mathrm{P} \frac{\mathrm{R} \mathrm{R}^{\prime}}{\left(\mathrm{R}+\mathrm{R}^{\prime}\right)} \frac{\left(1-v^{\prime}\right)}{\mathrm{E}}\right]^{1 / 3}
$$

The equation for $a$ is given in APPENDIX A, Eq. 8A as $\left[m=a^{*}\right.$ in Harris (9)]

$$
a=m\left[\frac{3}{2} \cdot \mathrm{P} \frac{\mathrm{R} \mathrm{R}}{\left(\mathrm{R}+\mathrm{R}^{\prime}\right)} \frac{\left(1-\nu^{2}\right)}{\mathrm{E}}\right]^{1 / 2}
$$

Thus, $b / a$ is given by

$$
\frac{b}{a}=\frac{n}{m}
$$

An equation for $m$ as a function of $\psi$ is given in Eq. 7. An equation of the polynomial fit for $n$ is

$$
\begin{aligned}
n & =1.00297-0.768404 \psi+0.68999 \psi^{2} \\
& -0.56492 \psi^{3}(0 \leqslant \psi \leqslant 0.94)
\end{aligned}
$$

A calculation for $\tau_{0}$ and the depth $z_{\tau_{0}}$ is based on data in Harris (9) and is

$$
\begin{aligned}
\tau_{0} & =\mathrm{f}_{1}(b / a) \frac{3 \mathrm{P}}{4 \pi a b} \\
f_{1}(b / a) & =0.50169-0.03725\left(\frac{b}{a}\right) \\
& -0.03811\left(\frac{b}{a}\right)^{2}
\end{aligned}
$$

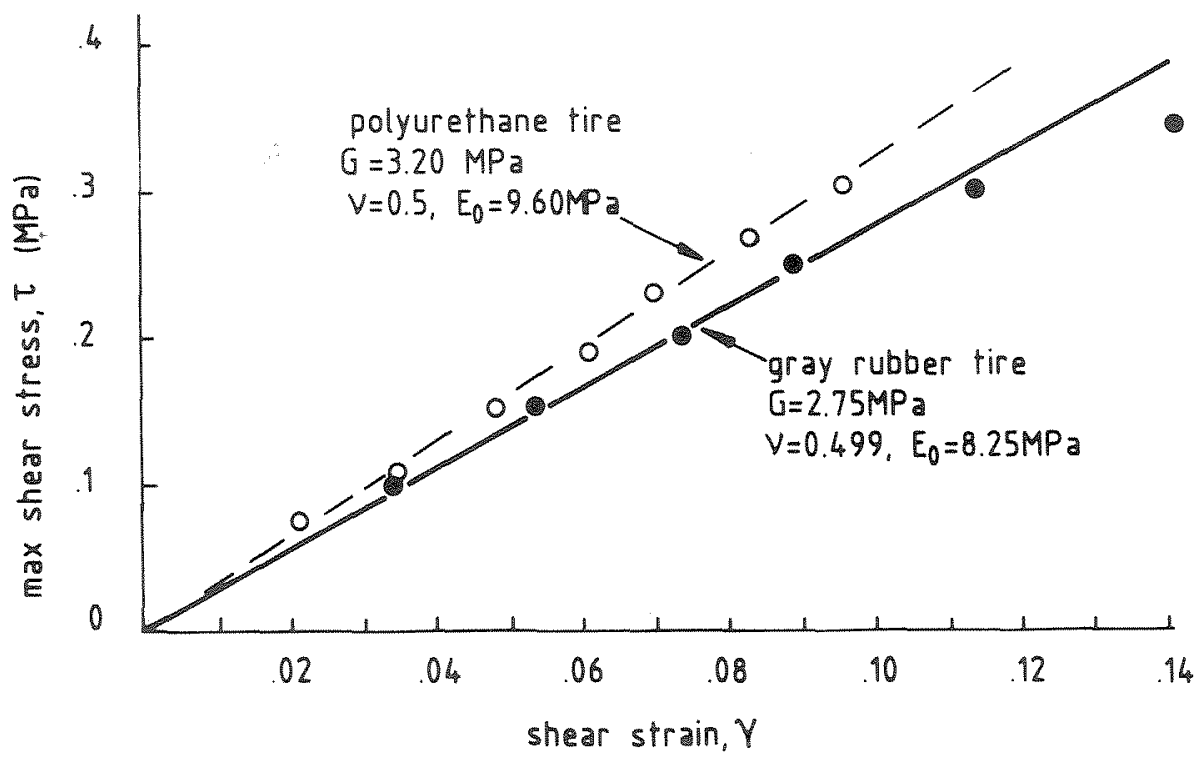




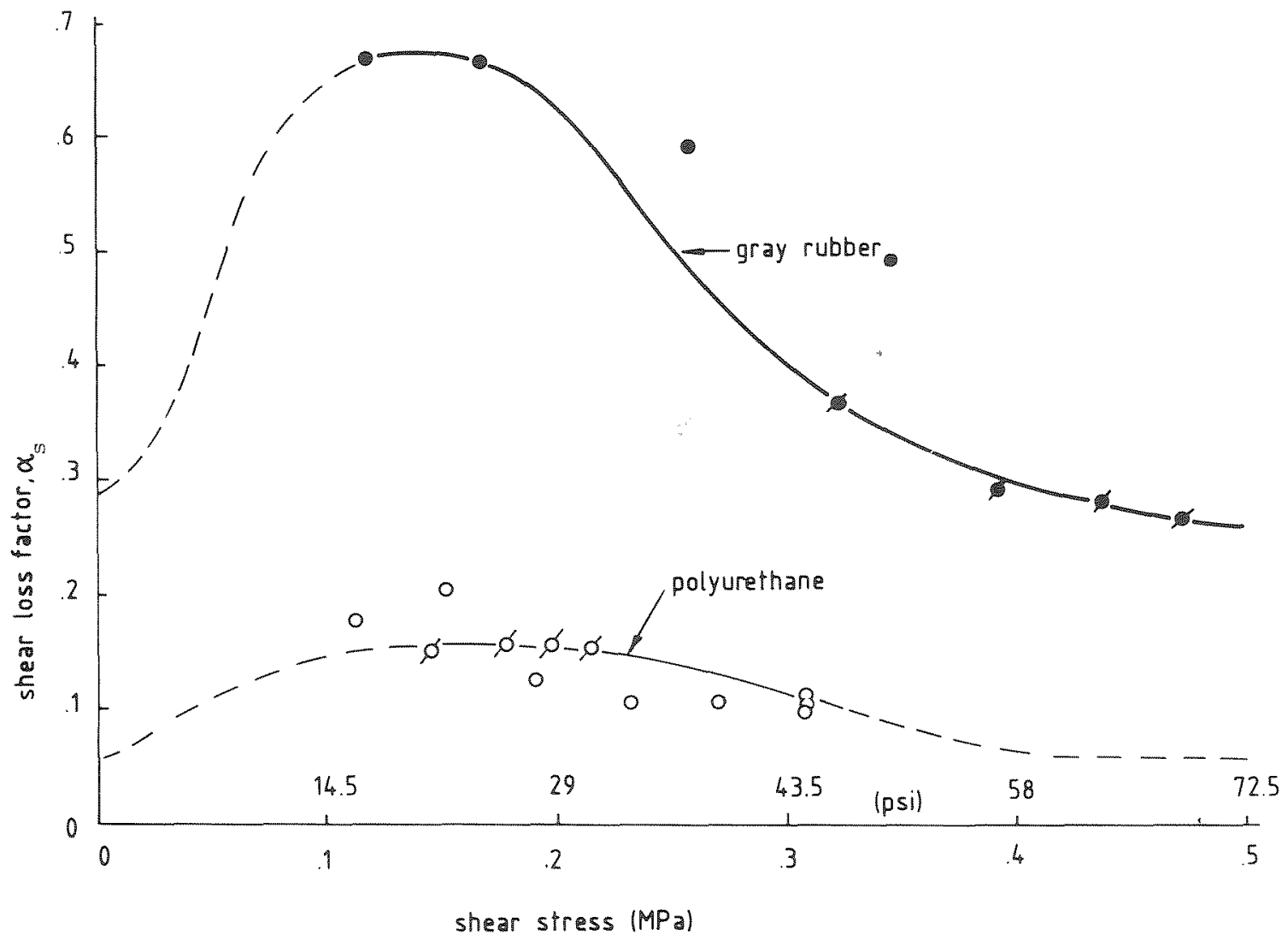

FIGURE 7

Shear loss factor from rolling resistance and torsional pendulum tests of wheelchair tires, $\omega=1-30 \mathrm{~Hz}$, room temperature.

and

$$
\begin{aligned}
\frac{z_{\tau_{0}}}{b} & =f_{2}(b / a) \\
f_{2}\left(\frac{b}{a}\right) & =0.50050-0.036632\left(\frac{b}{a}\right) \\
& -0.25956\left(\frac{b}{a}\right)^{2}+0.14685\left(\frac{b}{a}\right)^{3}
\end{aligned}
$$

The correlation of theoretical and experimental results in Figures 8 and 9 is based on predicting the shear loss factor correctly for the materials (Fig. 7). In theory, the torsional pendulum method can be used to predict the shear loss factor, but based on the scatter of results by this method, a more refined torsional pendulum test than was used is needed. However, once the material is characterized for shear loss factor, the results are very valuable in predicting the effects of changes in the tire design geometry. These results are discussed in the next section.

\section{Design Analysis}

Applying the rolling resistance theory of Eq. 5 for the two materials tested, gray rubber and polyurethane, gives an insight into the effect of changes in geometry on tire performance. In the design of a tire tread, the tread radius ( $\left.R^{\prime}\right)$ in the contact zone can be easily varied and will change the rolling resistance and the shear stress $\left(\tau_{0}\right)$ experienced by the tire.

The calculation for gray rubber is given in Figure 10. The test data point is for a current wheelchair tire design. If the radius of tire profile is increased, an increase in rolling resistance is predicted. However, the shear stress will decrease, which leads to a longer life before fatigue cracking becomes significant. A recommended design limit for fatigue of $0.35 \mathrm{MPa}$ is quoted by Freakley and Payne (3, p. 105). Based on this limit, the test tire is overstressed under the design conditions. A tire profile radius of 


\section{FIGURE 8}

Rolling resistance of solid gray rubber wheelchair tire versus load, room temperature.
FIGURE 9

Rolling resistance of polyurethane wheelchair tire versus load, room temperature.
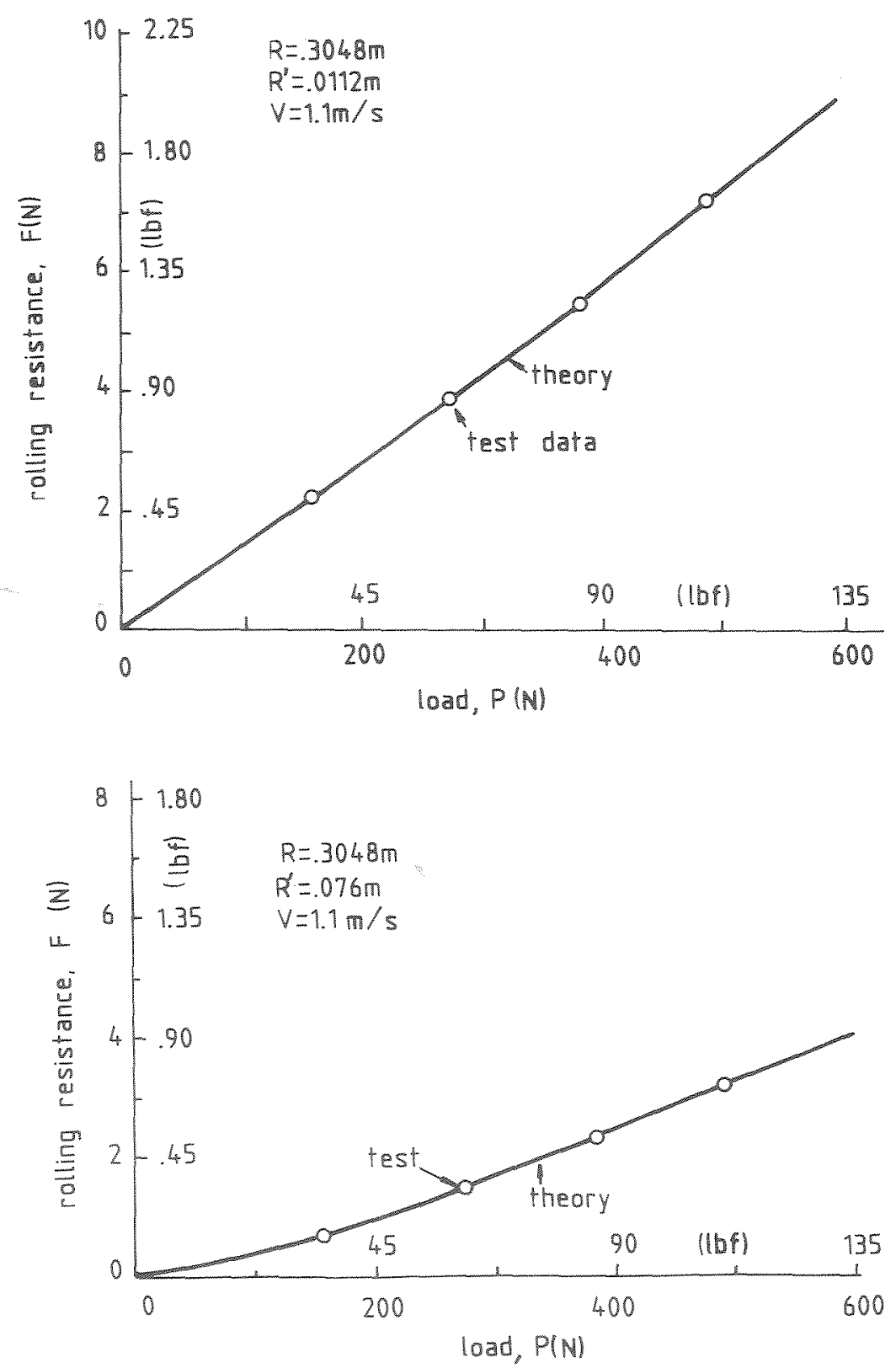

$\mathrm{R}^{\prime}=0.8$ inches results from the design limit stress, but this change will increase the rolling resistance by a factor of 1.2 .

Recommended shear design stresses for fatigue are given by Hirst (10). These are shown in Figure 11 for room temperature operation of a rubber with a modulus of rigidity, $\mathrm{G}=0.7 \mathrm{MPa}$. The analysis for shear stress fatigue is given in APPENDIX B.

Applying the Hirst criteria as modified for the gray rubber test tire from Figure 11 gives a tire life of $2.5 \times 10^{6} \mathrm{cycles}$ for a maximum shear stress of $0.35 \mathrm{MPa}$. This fatigue life translates into 4 years for the large rear wheel $(R=12 \mathrm{in})$ on a wheelchair averaging 2 miles per day and 1.4 years for the small front caster wheel $(\mathrm{R}=4 \mathrm{in}$ ). If the design shear stress for the caster wheel is reduced to $0.28 \mathrm{MPa}$, the fatigue life of the caster wheel will be increased to 4 years.

A design analysis for polyurethane is given in Figure 12. Although no useful fatigue data have been found in the literature, Wright and Cumming (24) note that high hardness solid polyurethane tires have a much higher load-bearing capacity than similar sized rubber tires. Smith (18) gives some comparative tear strength data for a natural rubber and polyurethane of similar 


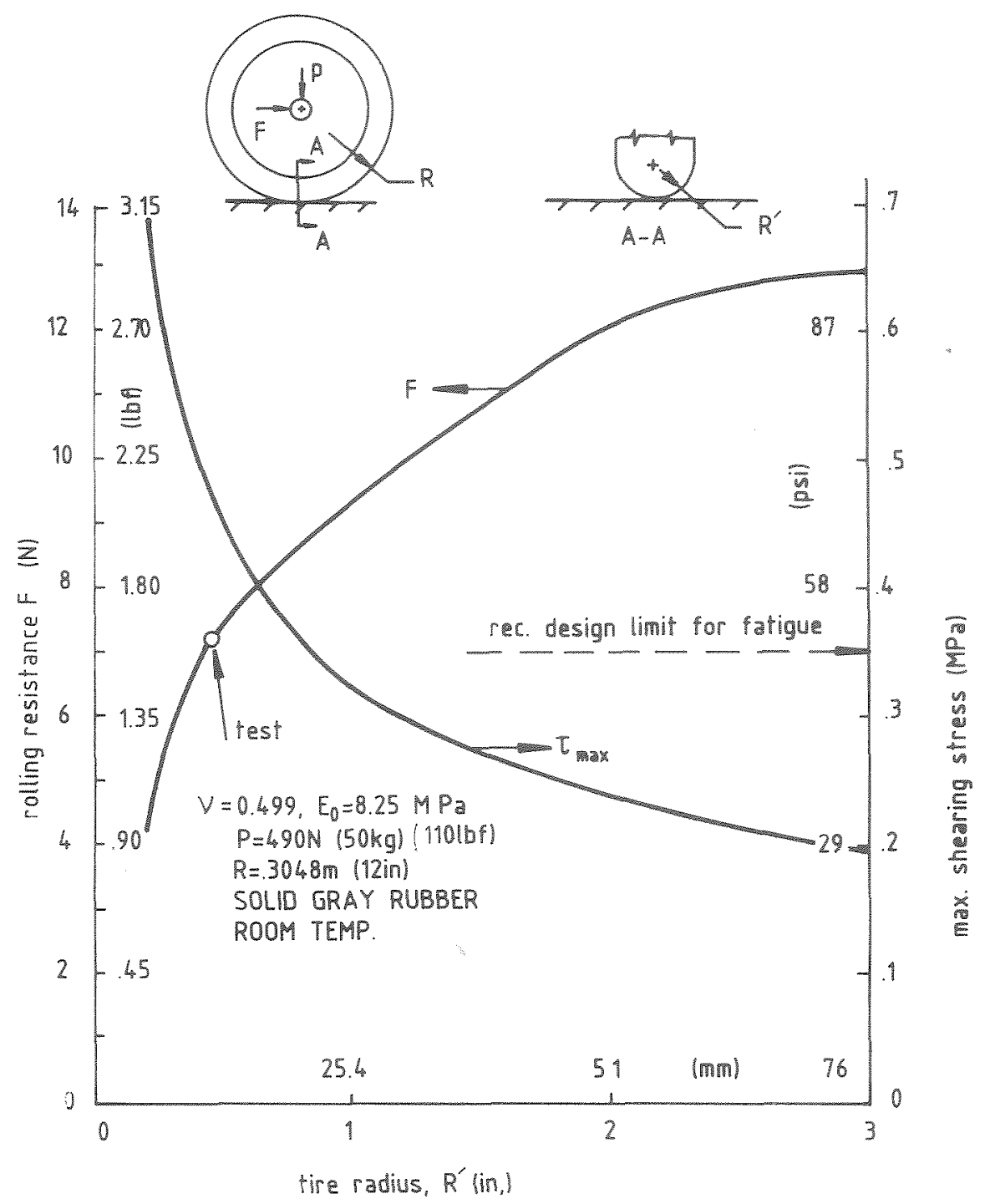

FICURE 10

Parameters for solid gray rubber tire design. hardness (65-68 Shore A). At room temperature, the polyurethane exhibits about one-third the tear strength of the natural rubber. It appears that the results for load and tearing are in contradiction. This can be rationalized by examining the hardness versus shear modulus curves for natural rubber and polyurethane.

The data in Figure 13 give small strain shear modulus for polyurethane calculated from Ref. (24, Fig. 10.5), and for rubber from (Ref. 3, Fig. AIV.2). Figure 13 shows that at high hardness the shear modulus is much higher for polyurethane than for rubber. Therefore, the strain-energy is lower at high loads for polyurethane than for rubber. For a tensile or shear tear test (2), the tear strength ( $\mathrm{T}$ ) is related to the strain-energy (W) and initial test cut length (c) by

$$
T=2 \pi W c
$$

For a rubber and a polyurethane with the same hardness of 67 Shore A. Smith (18) shows that the tear strength for carbon black-filled natural rubber is about three times that of the polyurethane at room temperature. Using $\mathrm{Eq} .26$ and data from Figure 13 of $\mathrm{G}^{\mathrm{p}}=3 \mathrm{MPa}$ and $\mathrm{G}^{\mathrm{NR}}=1.3 \mathrm{MPa}$ gives

$$
\frac{\sigma^{\mathrm{NR}}}{\sigma^{\mathrm{PU}}} \cong \sqrt{3 \frac{G^{\mathrm{NR}}}{G^{\mathrm{PV}}}}=1.14
$$

At a higher hardness, Eq. 27 and data from Figure 13 predict a much higher load capacity for polyurethane over rubber. 


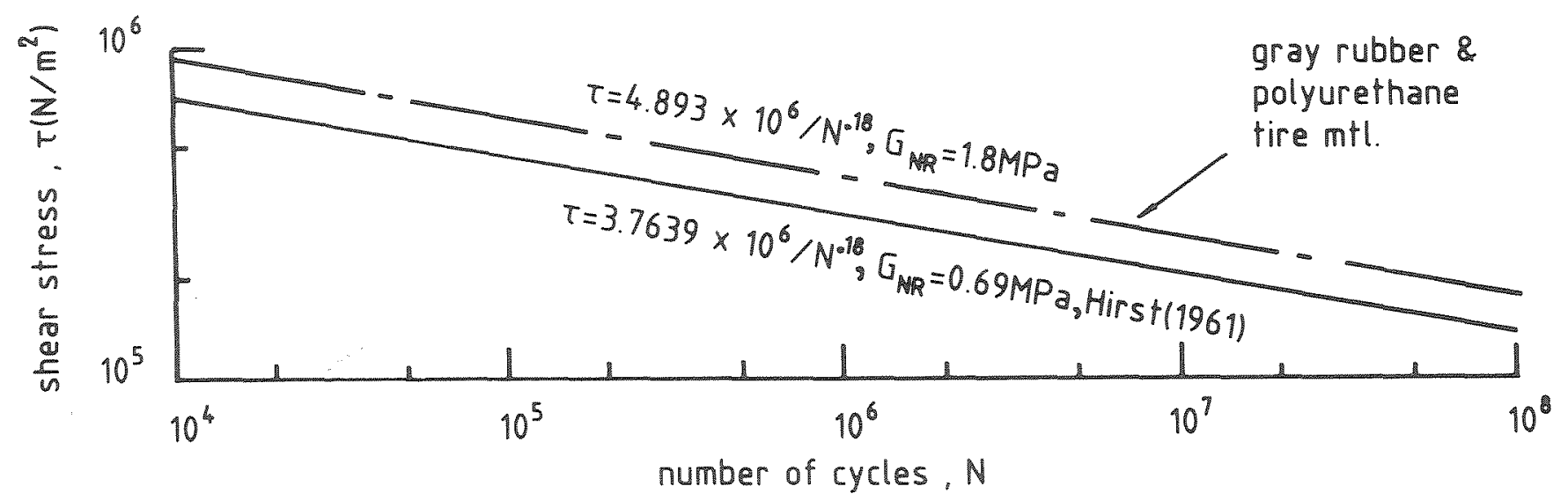

FIGURE 11

Fatigue stress range in shear.

The data used in Eq. 27 closely corresponds to the polyurethane tire material and equivalent natural rubber used for the gray rubber tire material in the fatigue analysis in APPENDIX $B$. Thus, these results predict that the gray rubber and polyurethane tire materials tested should have the same fatigue characteristics as shown in Figure 11.

Applying the modified Hirst criteria in Figure 11 for a four-year fatigue life, $2.5 \times 10^{\circ}$ cycles, the maximum shear stress on the large rear wheel of a wheelchair is $0.35 \mathrm{M} \mathrm{Pa}$. For the same life the maximum shear stress for the small caster wheel is $0.28 \mathrm{MPa}$. Figure 12 shows that the tire design stress can be increased from $0.21 \mathrm{MPa}$ to $0.35 \mathrm{MPa}$ with a reduction in rolling resistance of 60 percent by reducing the tire cross-section radius from 3 to $1.1 \mathrm{in}$. Such an improvement in rolling resistance for the solid polyurethane tire would compare very well with high-pressure pneumatic tires, which give the lowest rolling resistance measured [e.g., Thacker (20, Fig. 22)].

\section{Roughness}

So far, the surface has been assumed to be smooth and level. Johnson (11) points out that surface irregularities increase the rolling resistance because 1) the roughness intensifies the real contact pressure and 2) because the roughness requires energy to surmount the irregularities.

Most of the rolling resistance tests of wheelchairs reported used a treadmill device with a hard belt sliding on a flat steel surface. Additional tests were run to determine rolling resistance on other surfaces (20). The test results showed that there will be an increase in rolling resistance with respect to the treadmill by a factor of 1.55 for a relatively smooth-finished concrete floor and by a factor of 5.3 for a shortpile office carpet. The results do not vary much with total laden weight up to the maximum test load of 200 lbf $(890 \mathrm{~N})$ or speed up to $7 \mathrm{~km} / \mathrm{h}$ $(1.94 \mathrm{~m} / \mathrm{s})$.

One needs to be aware that these mechanical losses sustained on concrete or carpet are not necessarily of the same nature as the hysteresis losses in bulk deformation of the solid tire.

\section{DISCUSSION}

One of the most important results of this analysis is that the hysteresis rolling loss theory of Tabor is found to predict the rolling resistance of solid rubber wheelchair tires. The theory and experiment are in very good agreement. The wheelchair design engineer has a tool that contains all of the equations and test measurements needed for optimizing solid rubber tire design with respect to rolling resistance. The subject is complicated and has a long history of contradictory but plausible theories. However, for linearelastic tire materials, the hysteresis loss theory is a practical model for the rolling-resistance phenomenon. If the tire materials are viscoelastic, one must look at the viscoelastic rolling resistance theories [e.g., Moore (13)]. In most cases, 


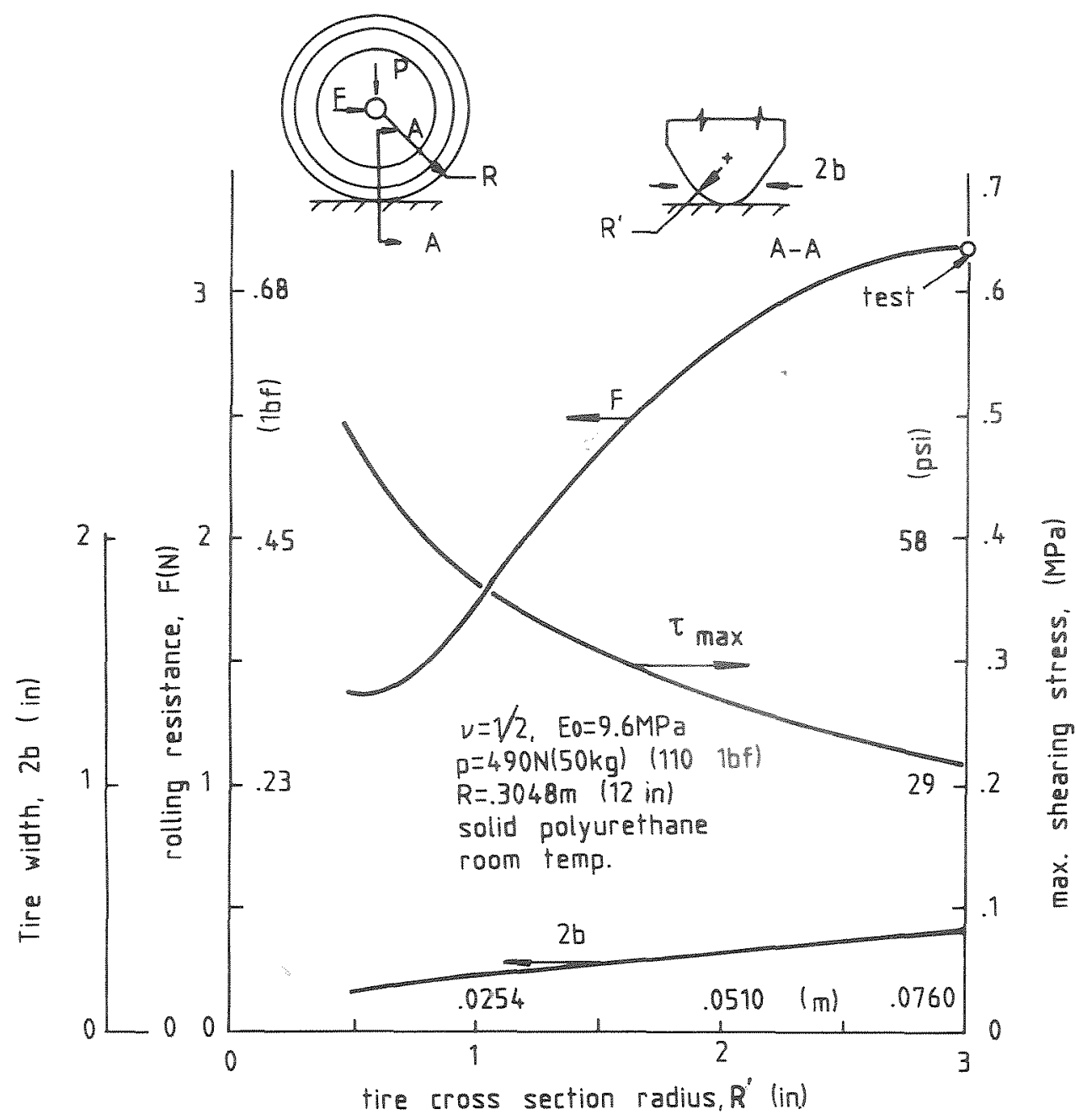

FIGURE 12

Parameters for polyurethane tire design.

highly viscoelastic materials are not favored for wheelchair tires. These materials tend to take on a deformation due to creep, which does not relax immediately and produces an audible thump on rolling.

Another important aspect of this analysis is the attempt to relate fatigue stress to tire design. This part of the paper is based on fracture mechanics and the relations between tearing strength and fatigue of rubbers. Unfortunately, there is few experimental data available, and the fatigue behavior of the wheelchair tire materials must be inferred from the existing information on natural rubber reinforced with carbon black. This is an area in need of further analysis and testing.

An important result of the wheelchair tire design study is that theory predicts that solid polyurethane tires will give the least rolling resistance of all current wheelchair tires. Advantage must be taken of the high load capacity of this material by reducing the radius of the tire profile in contact with the floor to an optimum value for the strain-energy density under load. The fatigue failure is due to shear stresses acting on flaws in the rubber. The maximum shear stress for a rolling tire occurs below the surface of the rubber, near both edges of contact. If the tire is sculptured in the area of the tread so that insufficient rubber is near the maximum shear stress regions, early failure due to crack growth may occur.

An area of tire material analysis not covered in this paper is abrasion resistance of the tire and resulting wear. Also, the effect of ozone and other chemicals is not considered. These additional topics of importance are reviewed extensively by 
FIGURE 13

Shear modulus versus hardness.

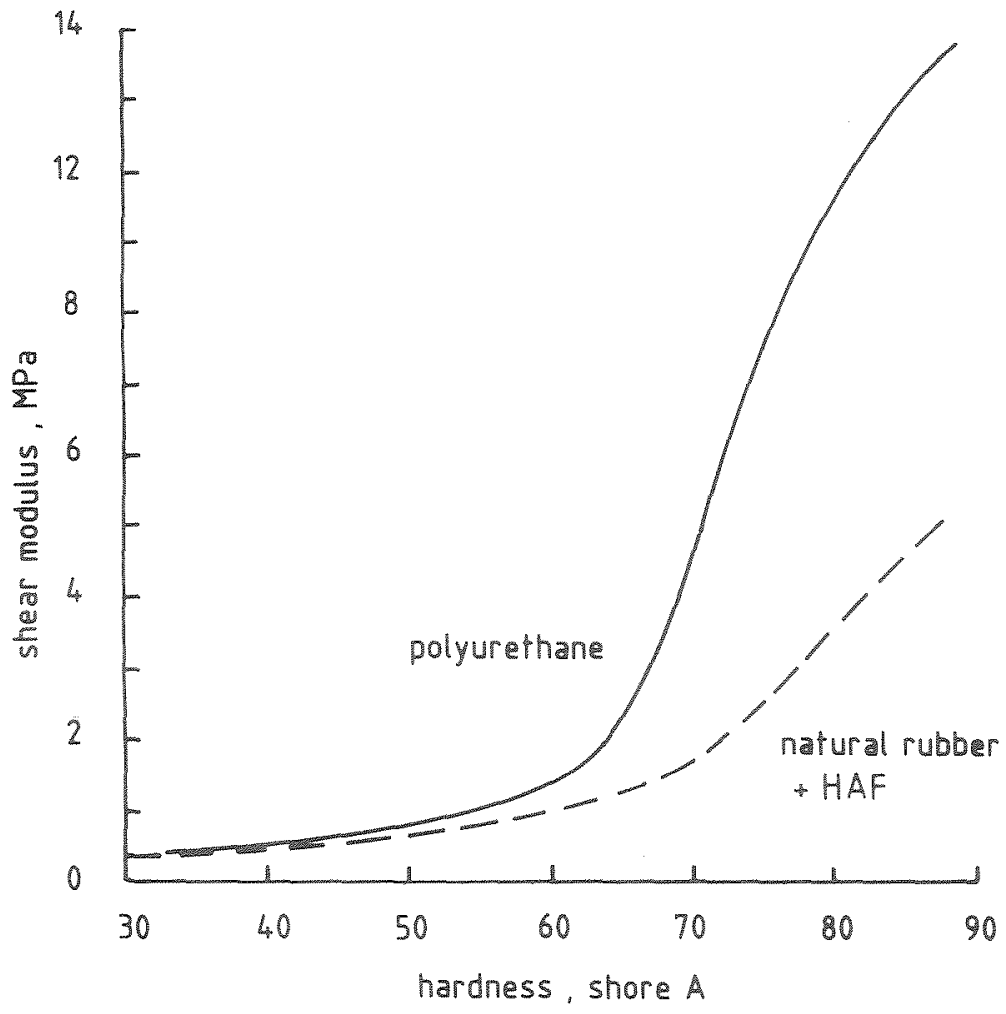

Differentiating with respect to $\mathrm{x}$, gives

$$
\frac{\delta \mathrm{w}}{\delta \mathrm{x}}=-\frac{\mathrm{x}}{\mathrm{R}}
$$

Changing sign to give the work done on the tire material, and for a differential area $\mathrm{dx}$ dy as shown in Figure 1A, the work is $p d x d y s x / R$, where $p$ is pressure, and the total work done in compressing the rubber in the front half of the ellipse is

$$
\phi=\frac{\mathrm{s}}{\mathrm{R}} \iint \mathrm{p} \mathrm{x} d \mathrm{x} d \mathrm{y}
$$

The pressure distribution [see Greenwood et al. (6) or Harris $(9$, p. 124)] (note missing $1 / 2$ in Harris) is

$$
p=\frac{3 P}{2 \pi a b}\left[1-\left(\frac{x}{a}\right)^{2}-\left(\frac{y}{b}\right)^{2}\right]^{1 / 2}
$$

Substituting Eq. $5 \mathrm{~A}$ into $4 \mathrm{~A}$ and integrating over the limits from $x=0$ to $a$, and $y=-b \sqrt{1-x^{2} / a^{2}}$ to $b \sqrt{1-x^{2} / a^{2}}$ gives

$$
\phi=\mathrm{s} \frac{3}{16} \frac{\mathrm{P}}{\mathrm{R}} \mathrm{a}
$$

The work that must be supplied is the work of hysteresis dissipation given by $\alpha \phi$; thus

$$
\mathrm{Fs}=\alpha \mathrm{s} \frac{3}{16} \frac{\mathrm{P}}{\mathrm{R}} a
$$




$$
\mathrm{F}=\alpha \frac{3}{16} \frac{\mathrm{P}}{\mathrm{P}} \mathrm{a}
$$

From the Hertz theory [e.g., see Timoshenko and Goodier (22) or Harris (9)] the equation for $a$ is

$$
a=\mathrm{m}\left[\frac{3}{2} \mathrm{P} \frac{\mathrm{R} \mathrm{R}}{\left(\mathrm{R}+\mathrm{R}^{\prime}\right)} \frac{\left(1-v^{2}\right)}{\mathrm{E}}\right]^{1 / 3}
$$

Substituting Eq. $8 A$ into $7 A$ results in

$$
\mathrm{F}=\alpha \frac{3}{16} \frac{\mathrm{P}^{+3}}{\mathrm{R}} \mathrm{m}\left[\frac{3}{2} \frac{\mathrm{R} \mathrm{R}^{\prime}}{\left(\mathrm{R}+\mathrm{R}^{\prime}\right)} \frac{\left(1-\nu^{\prime 2}\right)}{\mathrm{E}}\right]^{\mathrm{h}}
$$

where $m=f\left(R, R^{\prime}\right)$ and is given by Eqs. 6 and 7 in THEORY.

In Eq. 9A, the hysteresis loss factor $\alpha$ is impossible to measure for rolling elements. This problem is considered in more detail under Material Properties. However, it is fairly easy to measure the hysteresis loss factor in shear with a torsional pendulum. Greenwood et al. (6, Fig. 16) compare their theoretical and test results and find that $\alpha$ in rolling is $3.4 \alpha_{\mathrm{s}}$ for a cylinder and $2.5 \alpha_{\mathrm{s}}$ for a sphere $(6, \mathrm{p} .500)$. Treating the test data (6, Fig. 16) for short cylinders as effectively giving elliptical footprints, a plot of the rolling/torsion loss factor ratio is fit to the data and is shown in Figure 2A. Here it is shown that, for wheelchair tires, a factor of 2.5 will apply, and Eq. $9 \mathrm{~A}$ can be reduced to the final form shown in $\mathrm{Eq} .5$ of

$$
\mathrm{F}=2.5 \alpha_{\mathrm{s}} \frac{3}{16} \frac{\mathrm{P}^{4 / 3}}{\mathrm{R}} \mathrm{m}\left[\frac{3}{2} \frac{\mathrm{R} \mathrm{R}}{\left(\mathrm{R}+\mathrm{R}^{\prime}\right)} \frac{\left(1-v^{2}\right)}{\mathrm{E}}\right]^{1 / 3}
$$

Equation $10 \mathrm{~A}$ has been derived with wheelchair tires in mind. If the tire is essentially a rolling cylinder, then the equation will be different from Eq. 10A. In the case of cylinders, Greenwood et al. (6) have derived the appropriate equations. However, as shown by Greenwood's test data, when the ratio of effective b/a $<0.1$ (see Fig. 2A), the test results agree with the "long" cylinder theory; otherwise there is less agreement.

\section{APPENDIX B}

\section{Rubber Fatigue}

Davey and Payne (2) express the cut-growth characteristic of a rubber in terms of tearing energy $\mathrm{T}$, the strain-energy per unit volume necessary to create new surfaces by tearing. Fatigue is shown to be a function of cut-growth per deformation cycle originating from

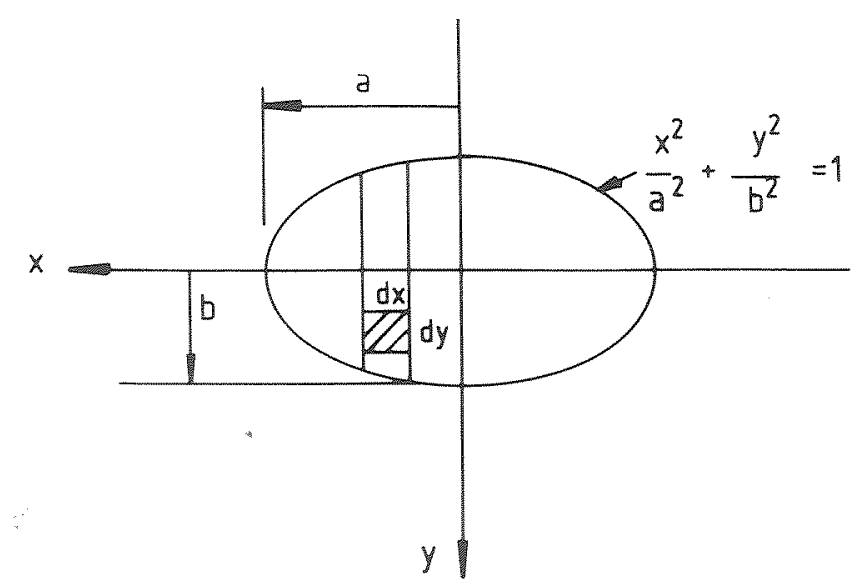

FIGURE 1A

Wheelchair tire footprint.

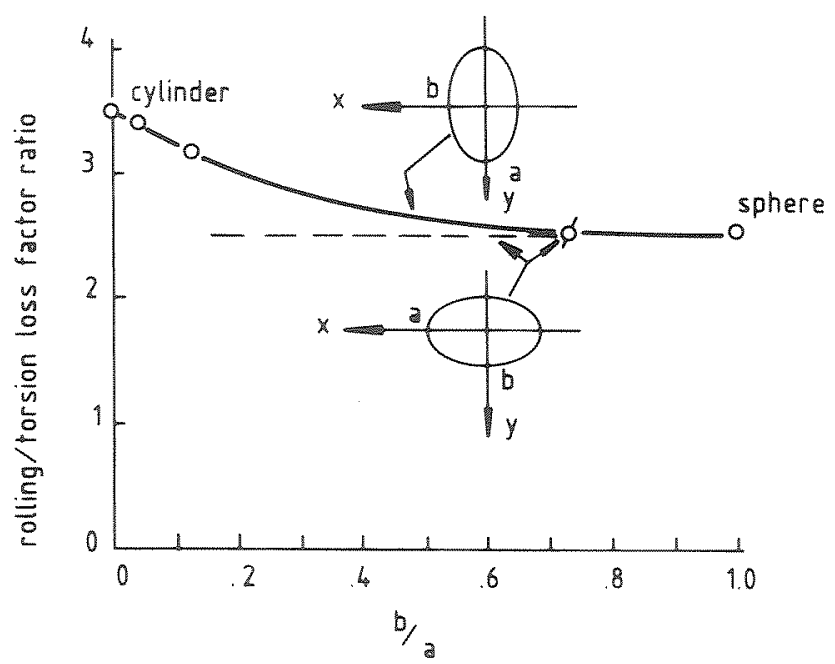

FIGUTE 2A

Relation between the loss factor in rolling to torsion.

small flaws in the rubber on the order of $10^{-5} \mathrm{~m}$ long. Williams (23) presents an analysis for cut-growth (crack growth). He notes that crack growth takes place when the tensile and/or shear strain-energy exceeds a critical intensity in the stress field local to the crack. Crack growth is not promoted by compressive stresses; in fact it appears that compressive stresses inhibit crack growth (2).

In the case of solid rubber wheelchair tires, the deformation stress field only involves compression and shear stresses. Dependency on these components suggests that the fatigue failure mechanism must be a shear strain-energy effect. Following the method presented by Davey and Payne (2) for tensile fatigue failure, a shear fatigue failure equation is developed as discussed below.

After a conditioning period of cyclic loading in shear, the crack growth per cycle of loading is assumed to be a power law function of the shear strain-energy. The 
Journal of Rehabilitation Research and Development Vol. 22 No. 3 July 1985

exponent $\mathrm{p}$ will be determined later. Thus,

$$
\mathrm{T}_{\tau}^{\mathrm{p}}=K_{0} \frac{\mathrm{dc}}{\mathrm{d} n}
$$

Williams (23) shows that the tearing energy in shear depends on the length of the crack, $c$, and the shear strain-energy per unit volume, $W_{\tau}$, in the region surrounding the crack. Therefore,

$$
\mathrm{T}_{\tau}=2 \pi \mathrm{W}_{\tau} \mathrm{c}
$$

Using Eqs. (1B) and (2B), the crack growth rate is

$$
\frac{\mathrm{de}}{\mathrm{d} n}=\frac{\left(2 \pi \mathrm{W}_{\tau} \mathrm{c}\right)^{\mathrm{p}}}{K_{0}}
$$

Separating variables and integrating, gives

$$
n=\frac{K_{0} /(\mathrm{p}-1)}{\left(2 \pi \mathrm{W}_{\tau}\right)^{\mathrm{p}}}\left[\frac{1}{\mathrm{c}_{0}^{\mathrm{p}-1}}-\frac{1}{\mathrm{c}^{\mathrm{p}-1}}\right]
$$

Since $c_{0}$ is the initial crack length, $c_{0}<c$. The fatigue life in terms of cycles to failure $\mathrm{N}$ is

$$
\mathrm{N}=\frac{K_{0} /(\mathrm{p}-1)}{\left(2 \pi \mathrm{W}_{\tau}\right)^{\mathrm{P}} \mathrm{c}_{0}{ }^{\mathrm{p}-1}}
$$

A shear stress fatigue equation developed from experience is given by Hirst (10). In S.I. units at room temperature operating conditions, the Hirst equation is

$$
\tau=\frac{3.7639 \times 10^{6}}{\mathrm{~N}^{0.18}},(\mathrm{G}=0.69 \mathrm{MPa})
$$

Comparing Eq. $6 \mathrm{~B}$ to $5 \mathrm{~B}$ shows that the exponent $p=2.78$. The theory of $\mathrm{Eq} .5 \mathrm{~B}$ supports the simple design equation suggested by Hirst where shear stress and life cycles are the significant variables.

To modify Eq. $6 \mathrm{~B}$ for gray rubber requires some interpretation. Naunton (14) observes that silicas are often credited with natural rubber reinforcing ability comparable with carbon black. For the same percentage of micron-size silicas, the rubber tear resistance is 90 percent of that of high abrasive furnace (HAF) black. Abrasion resistance is only 60 percent of that of HAF black. The hardness and the tensile strength is higher than that of HAF black. Gray rubber contains about 50 percent clay, and the corresponding natural rubber with 50 percent carbon black would have a shear modulus on the order of 270 p.s.i. (1.8 MPa) $(2$, Fig. 1.6). Hirst (10) gives a relative loading correction for $\mathrm{G}=270$ p.s.i. of 1.3. When applied to Eq. $6 \mathrm{~B}$, this gives

$$
\tau=\frac{4.893 \times 10^{6}}{N^{0.18}}
$$

where $\mathrm{N}$ is the number of cycles of loading and $\tau$ is the shear stress in $\mathrm{N} / \mathrm{m}^{*}$. Equation $7 \mathrm{~B}$ applies to a natural rubber reinforced with 50 percent carbon black having a shear modulus of $\mathrm{G}=270$ p.s.i. (1.8 MPa). It will also be assumed to apply to gray rubber with 50 percent clay having a higher shear modulus. In Figure 6 , the shear data for the test gray rubber gives $\mathrm{G}=2.75 \mathrm{MPa}$.

The gray rubber, with its higher shear modulus, should be able to carry a higher load. However, to be on the conservative side, we will assume that Eq. 7B can be applied to the test gray rubber material. A program of testing is recommended to confirm the use of Eq. 7B for gray rubber containing 50 percent clay.

\section{NOMENCLATURE}

a one-half contact length, $m$

A Equation $1 \mathrm{~A}, \mathrm{~m}^{1}$

b contact length, $\mathrm{m}$

B Equation $1 \mathrm{~A}, \mathrm{~m}^{-1}$

c tear length, $m$

$c_{0} \quad$ initial tear or flaw length, $m$

C Equation 1A, m

d $2 \mathrm{a}, \mathrm{m}$

De Deborah Number

E modulus of elasticity, $\mathrm{N} / \mathrm{m}^{2}$

$\mathbb{E}_{0} \quad$ modulus of elasticity at $\epsilon=0, \mathrm{~N} / \mathrm{m}^{2}$

$f \quad$ coefficient of rolling resistance

$\mathrm{F} \quad$ rolling resistance, $\mathrm{N}$

$\mathrm{G}$ modulus of rigidity (shear), $\mathrm{N} / \mathrm{m}^{2}$

$\mathrm{J}$ polar moment of inertia, $\mathrm{m}^{4}$

Jo Johnson Number

$k$ rolling resistance coefficient, $\mathrm{m}$

$K_{0} \quad$ tearing coefficient, S.I. units

$\mathrm{L} \quad$ torsional spring length, $\mathrm{m}$

$m$ contact area coefficient

n

$\mathrm{N}$

p

$\mathrm{P}$

$\mathrm{R}$

$R_{e} \quad$ equivalent radius, $m$

$R^{\prime} \quad$ tire tread profile radius at contact, $m$

$\mathrm{s}$

$t$

$\mathrm{T}$

Tr

U

V cycles or contact area coefficient

number of cycles

pressure, $\mathrm{N} / \mathrm{m}^{2}$

load, N

tire radius, $m$

tire tread prof
path length, $m$

time, $s$

tearing strength, $\mathrm{N} / \mathrm{m}$

tearing strength in shear, $\mathrm{N} / \mathrm{m}$

energy, $\mathrm{N}-\mathrm{m}$

velocity, $\mathrm{m} / \mathrm{s}$ 


$\begin{array}{ll}W & \text { contact displacement, } \mathrm{m} \\ W & \text { strain energy density, } \mathrm{N}-\mathrm{m} / \mathrm{m}^{2} \\ W_{\tau} & \text { strain energy density in shear, } \mathrm{N}-\mathrm{m} / \mathrm{m}^{3} \\ \mathrm{x} & \text { coordinate, } \mathrm{m} \\ \mathrm{y} & \text { coordinate, } \mathrm{m} \\ \mathrm{z} & \text { coordinate, } \mathrm{m} \\ \alpha & \text { hysteresis loss factor } \\ \alpha_{\mathrm{s}} & \text { hysteresis loss factor in shear } \\ \gamma & \text { shear strain } \\ \delta & \text { deflection, } \mathrm{m} \\ \delta_{0} & \text { deflection, } \mathrm{m} \\ \mathrm{tan} \delta & \text { loss modulus } \\ \epsilon & \text { strain } \\ \theta & \text { torsional amplitude, radians } \\ \lambda & \text { logarithmic decrement } \\ v & \text { Poisson's ratio } \\ \sigma & \text { stress, N/m }{ }^{2} \\ \tau & \text { shear stress, } \mathrm{N} / \mathrm{m}^{2} \\ \tau_{0} & \text { maximum orthogonal shear stress, } \mathrm{N} / \mathrm{m}^{2} \\ \tau_{\mathrm{r}} & \text { d/V, s } \\ \tau_{\mathrm{m}} & \text { relaxation time constant, } \mathrm{s} \\ \tau_{\mathrm{y}} & \text { yield shear stress, } \mathrm{N} / \mathrm{m}^{2} \\ \tau_{\mathrm{zx}} & \text { shear stress, } \mathrm{N} / \mathrm{m}^{2} \\ \phi & \text { work per unit distance, } \mathrm{N}-\mathrm{m} / \mathrm{m} \\ \psi & \text { tire geometry factor } \\ & \end{array}$

\section{ACKNOWLEDGMENTS}

We extend our appreciation to Peter J. Outzs and Mehdi Mostaghimi for their work in collecting and reducing much of the experimental data.

Dr. Kauzlarich thanks the staff of the Tribology Centre, University College of Swansea, UK, for the use of their facilities during the preparation of this paper; he also acknowledges with great appreciation the correspondence with James Greenwood and K.L. Johnson of Cambridge University on points of detail concerning this paper.

\section{RETERENCES}

1. Coulomb CA: Theorie des machines simples. Mémoires de Mathématique et de Physique de l'Academie des Sciences, t 10, 1785, pp. 161-331.

2. DAVEY AB, PAYNE AR: Rubber in Engineering Practice, Englewood, NJ: Applied Science, 1964.

3. FREAKLEY PK, PAYNE AR: Theory and Practice of
Engineering with Rubber. Englewood, NJ: Applied Science, 1978.

4. GILES CG, SAEBY B: Rubber hysteresis and skidding resistance. Engineering 186: 840-842, 1958.

5. Greenwood JA: Personal communication, Nov. 1984.

6. Greenwood Ja, Minshall H, Tabor D: Hysteresis losses in rolling and sliding friction. Proc Roy Soc 259A: $480-507,1961$.

7. GREENwOOD JA, TABOR D: The friction of hard sliders on lubricated rubber: The importance of deformation losses, Phys Soc London Proc 71: 989-1001, 1958.

8. HaMILTON GM: Explicit equations for the stress beneath a sliding spherical contact. Proc Inst Mech Eng $197 \mathrm{C}: 53-54,1983$.

9. HARRIS TA: Rolling Bearing Analysis. New York: Wiley, 1966.

10. HIRst AJ: Practical applications of the dynamic properties of rubber. In: The Applied Science of Rubber, WJS Naunton (ed.). London: Arnold, 1961, pp. 587708.

11. Johnson KL: Contact Mechanics. London: Cambridge University Press, 1985.

12. KRAGElsky IV, DOBYCHIN MN, Kombalov VS: Friction and Wear Calcalation Methods. New York: Pergamon, 1982.

12a. KYLE CR, VAN VALKENBURG; Rolling resistance. Bicycling Mag. May, 1985, 140-152.

13. MoORE,DF: The Friction and Lubrication of Elastomers. New York: Pergamon, 1972.

14. NAUNTON WJS(ed.): The Applied Science of Rubber. London: Arnold, 1961.

15. Pormsky H: Stresses and deflections of cylindrical bodies in contact with application to contact of gears and of locomotive wheels. $J$ Appl Mech 17: 191-201, 1950.

16. RETI L(ed.): The Unknown Leonardo. New York: McGraw-Hill, 1974.

17. SCHURING DJ: The rolling loss of pneumatic tires. Rubber Chem Technol 53: 600-727, 1980.

18. SMITH FM: Properties of elastomers up to $550^{\circ} \mathrm{F}$. Rubber World 139: 533-541, 1959.

19. TABOR D: Elastic work involved in rolling a sphere on another surface Br J Appl Phys 6: 79-81, 1955.

20. THACKER JG: Measurement of Wheelchair Rolling Resistance. University of Virginia Rehabilitation Engineering Center Report UVA-REC-107-83, Sept. 1984.

21. THOMPSON WT: Theory of Vibrations with Applications (2nd ed.). Englewood Cliffs, NJ: Prentice-Hall, 1981.

22. TIMOSHENkO S, GOODIER JN: Theory of Elasticity (2nd ed.). New York: McGraw-Hill, 1951.

23. Williams JG: Stress Analysis of Polymers (2nd ed.). Halstead, 1980. (Ellis Horwood Series in Engineering Science.)

24. Wright P, Cumming APC: Solid Polyurethane Elastomers. Maclaren, 1969.

25. YOUNG RJ: Introduction to Polymers. London: Chapman \& Hall, 1981. 